\title{
Research on the End Surface Dent of the Main Shaft Forging
}

\author{
Liyong NI, Longjiang NIU*, Daoxiang QIAN, Suoging YU, Chenyu YE, Yibin CAI
}

\begin{abstract}
In the process of the stretching of the shaft forgings, if the process parameters are not properly selected, the end-face dent will take place. The end-face dent affects the performance of large forgings and leads to much material wasting. Finite element method was employed to perform numerical simulation of the stretching of a main shaft with an upper flat anvil and a lower V-shaped anvil. The orthogonal test table was designed by selecting the anvil width, the Reduction ratio and the feed as influencing factors. Accordingly, simulations were carried out to solve the end-face dent values under different parameter combinations. The analysis showed that the optimal parameter combination gave an anvil width ratio of 0.75 , a Reduction ratio of 0.2 , and an initial feed of $300 \mathrm{~mm}$. Through extremum difference analysis, it was found that among the three factors are the feed, the reduction ratio, and the anvil width ratio in the decreasing order of the influence on the end- face dent. Comprehensive analysis showed that when the anvil is relatively narrow, increasing the relative feed can reduce the end-surface dent remarkably. It is advisable that during the stretching of shaft forgings with a flat upper anvil and a V-shaped lower anvil, the combination of the anvil width ratio of 0.75 , the reduction ratio of 0.2 , and increasing the feed can reduce the end-face dent, thereby reducing the end cutting and saving material costs.
\end{abstract}

Keywords: dent; finite element method; heavy forgings; stretching

\section{INTRODUCTION}

In the production of shaft forgings, stretching is the most important tool. It is widely used. In the $1970 \mathrm{~s}$, through embedding corresponding sensors in plasticine, the stress distribution of the workpiece in the flat anvil stretching under different anvil width ratios was tested and analyzed. The Mannesmann effect was found in the experimental results [1]. In addition to the study on flat anvil stretching, researchers have gradually put forward various forging methods with shaped anvils. The stretching method with upper flat anvils and lower V-shaped anvils was developed. Later, FM forging method, WHF forging method, KD forging method, JTS forging method and so on have emerged $[2,3]$. These methods have been applied to the production of heavy forgings and have achieved noticeable effects. Among them, the WHF method, the JTS method, and the FM method are the most popular.

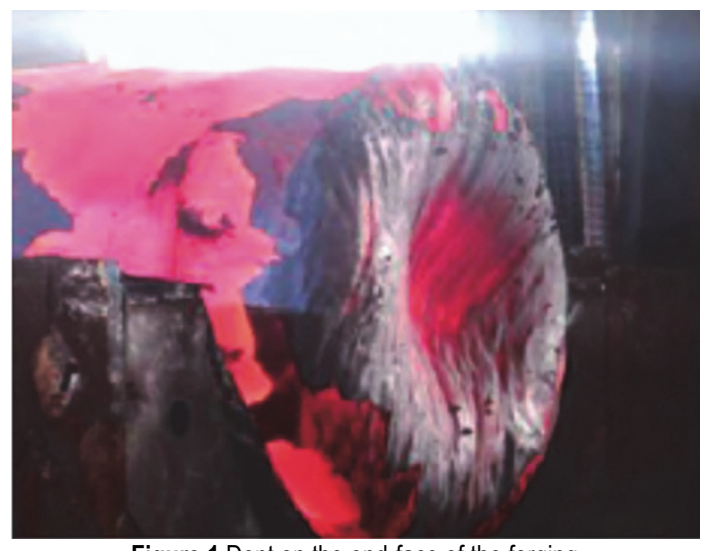

Figure 1 Dent on the end-face of the forging

During stretching of shaft forgings, geometry of the formed workpieces deviates from the desired target geometry, due to complex interactions between tools and billets which result in inhomogeneous temperature and stress fields. Therefore, the development of forging tools requires an iterative adaptation process through a large number of revisions in the tool geometry, which escalates the resulting costs [4]. For example, end-face dents could appear, as shown in Fig. 1 [5-8]. This geometry deviation seriously affects the performance of large forgings and wastes a large amount of steel. In order to produce hightemperature forgings with accurate shape and size, some countries developed non-contact optical geometry measurement techniques and methods based on laser scanning, machine vision and so on [9-14].

\section{FINITE ELEMENT MODEL}

The round billet is made of AISI 1045 steel and the anvil, AISI-H-13 hot-working die steel. The complete finite element model is shown in Fig. 2. The round billet has a diameter of $D=1000 \mathrm{~mm}$, and an upper flat and lower v-shaped anvils were used, as shown in Fig. 3 and 4. Their length $l=1200 \mathrm{~mm}$, width $B=500 \mathrm{~mm}$, and height $h=300$ $\mathrm{mm}$. The anvil width ratio is $a=B / D=0.5$. The angle of the $\mathrm{V}$-shaped anvil is $\beta=120$, and its opening width $B_{2}=$ $650 \mathrm{~mm}$. To prevent the round billet from flying away or slipping in the simulation, the nodes in the square area at the rear end of the round billet are constrained, and the rest are free.

The Reduction ratio chosen is 0.2 , and the initial feed of the anvil is $300 \mathrm{~mm}$. After that, the anvil feed is $320 \mathrm{~mm}$, $340 \mathrm{~mm}$, and so on. The billet rotates $45^{\circ}$ after each bite. The billet's initial temperature is $1200{ }^{\circ} \mathrm{C}$, and the hot forging conditions were assigned to between the billet and the upper and lower anvils. The friction coefficient between them is 0.3 .

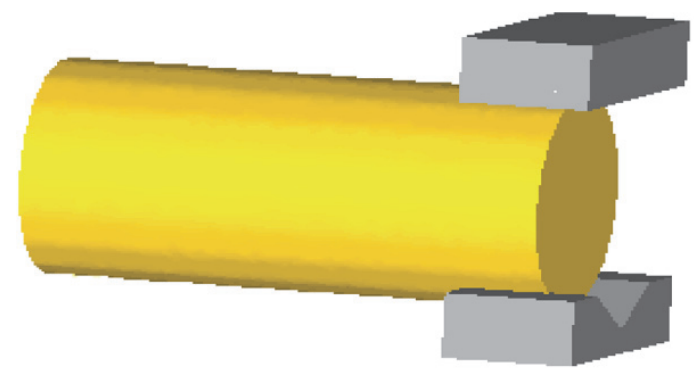

Figure 2 Finite element model of the stretching with flat upper and lower Vshaped anvils 

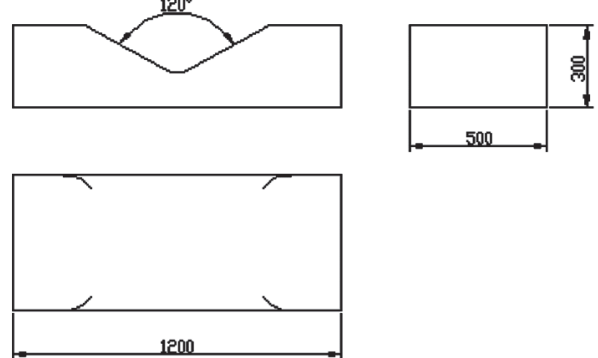

Figure 3 Model of the V-shaped anvil

\section{NUMERICAL SIMULATION RESULTS}

\subsection{Geometric Deformation}

Under the above process conditions, the end faces of the billet suffered dent defects, as shown in Fig. 4.

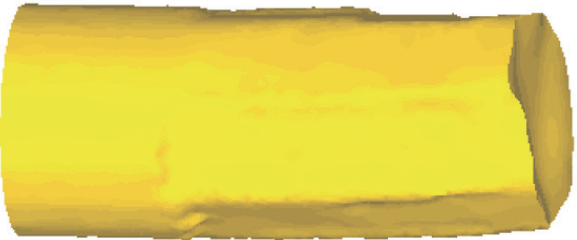

Figure 4 The end-face with dent

\subsection{Stress and Equivalent Strain Analysis}

Three-direction stress and equivalent strain distributions at the end of the stretching are shown in Fig. 5. Although tensile stresses can be seen in all directions, they were rare on the outer surface of the forging, which is beneficial to prevent the occurrence of defects such as cracks. In the center of the main shaft forging the equivalent strain reached about 1.1 while for the one to determine whether a forging is acceptable, the criteria is that the equivalent strain of the center of the forging should be above 0.2 [6]. Therefore, the above process scheme ensures the forging penetration efficiency (FPE) of the forging, and the forming scheme satisfies the quality requirements for the forging. In actual production, not only is the FPE in the center of the forging high enough, but the amount of end face dent needs to be reduced in order to increase the utilization rate of materials. Therefore, this process requires further optimization.

\section{USING ORTHOGONAL METHOD TO OPTIMIZE PROCESS PARAMETERS}

\subsection{Parameter Selection}

According to the literature [5], the three major influencing factors were studied:

(1) Anvil width ratio design: the anvil width is the ratio of the anvil width to the diameter of the billet. The anvil widths were determined to be: $500 \mathrm{~mm}, 750 \mathrm{~mm}, 1000 \mathrm{~mm}$ and the corresponding fillet radii are $50 \mathrm{~mm}, 75 \mathrm{~mm}, 100$ $\mathrm{mm}$.

(2) Reduction ratio. According to the anvil lengths, the reductions used were: $10 \%, 15 \%$ and $20 \%$.

(3) Feed. The initial feed is $300 \mathrm{~mm}$, and the successive feed is $320 \mathrm{~mm}, 340 \mathrm{~mm}$ and the like.
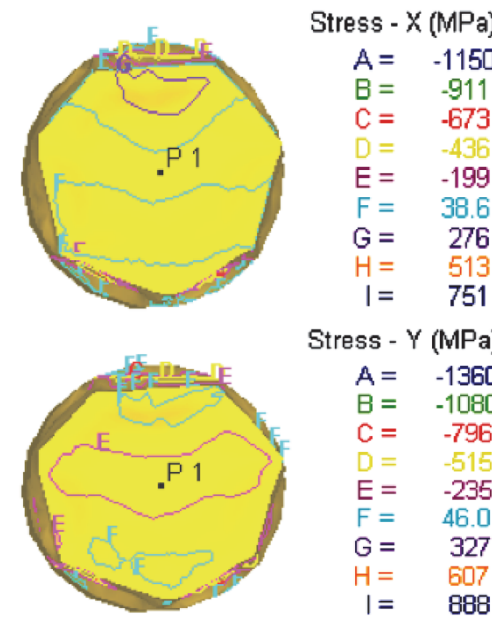

Stress - Y (MPa)

$A=-1360$

$\mathrm{B}=-1080$

$\mathrm{C}=-796$

$\mathrm{D}=-515$

$E=-235$

$\mathrm{F}=46.0$

$G=327$

$\mathrm{H}=607$

$1=888$

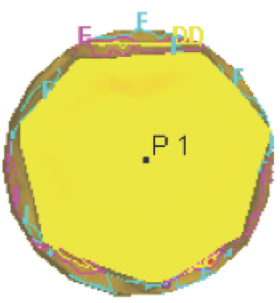

Stress - Z (MPa)

$A=-1030$

$\mathrm{B}=-810$

$\mathrm{C}=-590$

$\mathrm{D}=-370$

$\mathrm{E}=$

$F=69.9$

$G=290$

$\mathrm{H}=510$

$I=730$

Strain - Effective $(\mathrm{mm} / \mathrm{mm})$

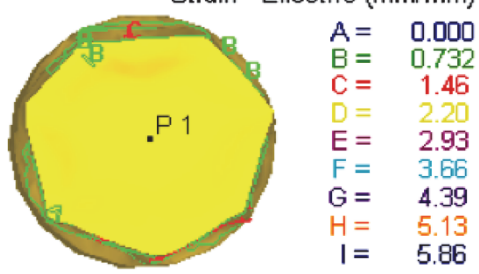

Figure 5 Three-direction stress and equivalent strain distributions at the end of the stretching of the main shaft forging

\subsection{Orthogonal Method Design and Calculation Analysis}

The orthogonal design was adopted to arrange the schemes and analyze the scheme results [16]. And the orthogonal table was selected to arrange the schemes. An orthogonal table $\mathrm{L}_{9}(3)^{3}$ was constructed and shown in Tab. 1. Various parameters listed can form 9 simulation schemes. Finally, the most influential factor and the optimal combination of parameters can be achieved through extremum difference analysis.

Table 1 Orthogonal Table $\mathrm{L}_{9}(3)^{3}$

\begin{tabular}{|c|c|c|c|c|c|c|}
\hline Scheme NO & Column NO.1 & Reduction ratio / \% & Column NO. 2 & Anvil width / mm & Column NO.3 & Initial feed $/ \mathrm{mm}$ \\
\hline 1 & \multirow{3}{*}{ A1 } & 10 & B1 & 500 & $\mathrm{C} 1$ & 300 \\
\hline 2 & & 10 & B2 & 750 & $\mathrm{C} 2$ & 390 \\
\hline 3 & & 10 & B3 & 1000 & $\mathrm{C} 3$ & 490 \\
\hline 4 & \multirow{3}{*}{ A2 } & 15 & B1 & 500 & $\mathrm{C} 2$ & 390 \\
\hline 5 & & 15 & $\mathrm{~B} 2$ & 750 & $\mathrm{C} 3$ & 490 \\
\hline 6 & & 15 & B3 & 1000 & $\mathrm{C} 1$ & 300 \\
\hline 7 & \multirow{3}{*}{ A3 } & 20 & B1 & 500 & C3 & 490 \\
\hline 8 & & 20 & $\mathrm{~B} 2$ & 750 & $\mathrm{C} 1$ & 300 \\
\hline 9 & & 20 & B3 & 1000 & $\mathrm{C} 2$ & 390 \\
\hline
\end{tabular}


The 9 parameter combinations for the 9 schemes are as follows (represented with letters):

\section{$\mathrm{A} 1 \mathrm{~B} 1 \mathrm{C} 1$ A1B2C2 A1B3C3 \\ $\mathrm{A} 2 \mathrm{~B} 1 \mathrm{C} 2$ A2B2C3 A2B3C1 \\ $\mathrm{A} 3 \mathrm{~B} 1 \mathrm{C} 3$ A3B2C1 A3B3C2}

\subsection{Simulations and Results}

The $\mathrm{A} 3 \mathrm{~B} 2 \mathrm{C} 1$ scheme was taken as an example to demonstrate the deformation process of the forging. In this scheme, the initial feed is $300 \mathrm{~mm}$, and the following feeds are $320 \mathrm{~mm}, 340 \mathrm{~mm}$, and so forth. After each bite, the billet rotates $45^{\circ}$, and totally, it will rotate 8 times. round cross-section becomes approximately oval. The axial elongation is relatively obvious and the end-face dent has basically formed, and a certain bulge appears in the areas adjacent to the anvils. The stretching process is shown in Fig. 6.

(2) The bite on the billet after $45^{\circ}$ rotation leads to more elongation, and the end face dent deepens, as shown in Fig. 7.

(3) The anvil presses down after another $45^{\circ}$ of rotation of the billet. The original round cross section has changed into an irregular shape. The forging has elongated axially and the final end-face dent has formed as shown in Fig. 8.

(1) The flat anvil presses down on the round billet, the

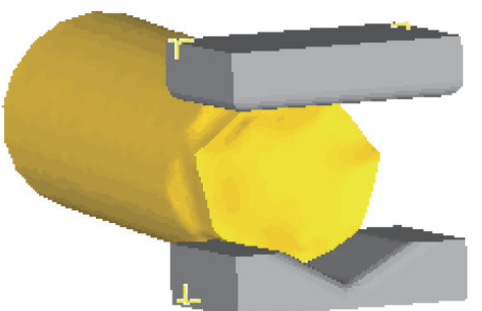

a) The first feed

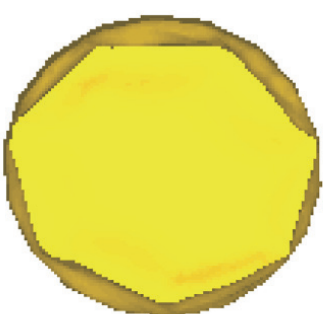

b) The cross-sectional shape

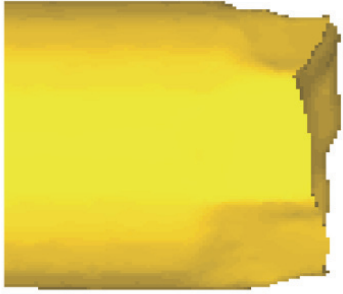

c) The dent has basically formed

Figure 6 Deformation in the first feed of the scheme A3B2C1

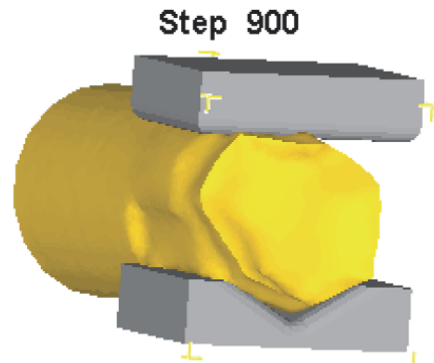

a) The second feed

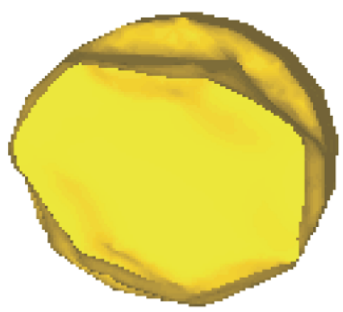

b) The cross-sectional shape

Figure 7 Deformation in the second feed in the scheme A3B2C1

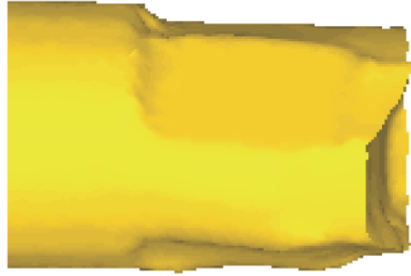

c) End-face dent deepens

Step 1150

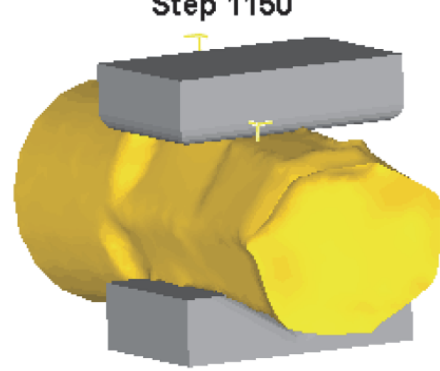

a) The third feed

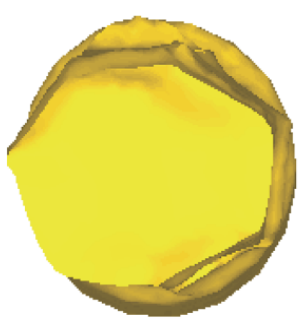

b) The cross-sectional shape

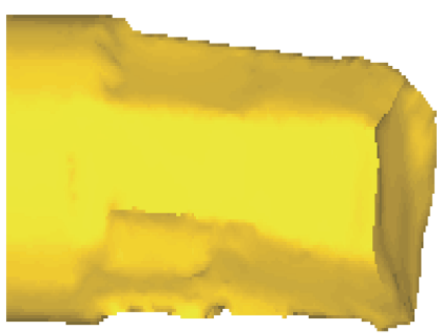

C) The final end-face dent

Figure 8 Deformation in the third feed in the scheme A3B2C1

Simulations results of the 9 schemes are listed in Tab. 2 .

Table 2 End-face dent depths from 9 simulations

\begin{tabular}{|c|c|c|}
\hline NO & Scheme number & End-face dent depths $/ \mathrm{mm}$ \\
\hline 1 & $\mathrm{~A} 1 \mathrm{~B} 1 \mathrm{C} 1$ & 34.41 \\
\hline 2 & $\mathrm{~A} 1 \mathrm{~B} 2 \mathrm{C} 2$ & 44.90 \\
\hline 3 & $\mathrm{~A} 1 \mathrm{~B} 3 \mathrm{C} 3$ & 32.40 \\
\hline 4 & $\mathrm{~A} 2 \mathrm{~B} 1 \mathrm{C} 2$ & 68.15 \\
\hline 5 & $\mathrm{~A} 2 \mathrm{~B} 2 \mathrm{C} 3$ & 64.86 \\
\hline 6 & $\mathrm{~A} 2 \mathrm{~B} 3 \mathrm{C} 1$ & 40.40 \\
\hline 7 & $\mathrm{~A} 3 \mathrm{~B} 1 \mathrm{C} 3$ & 52.63 \\
\hline 8 & $\mathrm{~A} 3 \mathrm{~B} 2 \mathrm{C} 1$ & 20.94 \\
\hline 9 & $\mathrm{~A} 3 \mathrm{~B} 3 \mathrm{C} 2$ & 58.63 \\
\hline
\end{tabular}

It can be seen that the scheme $\mathrm{A} 3 \mathrm{~B} 2 \mathrm{C} 1$ produced the smallest value of the end-face dent depth. In this scheme, the reduction ratio is $20 \%$, the anvil width of $750 \mathrm{~mm}$, and the initial feed of $300 \mathrm{~mm}$.

The corresponding best parameters are the combination of an anvil width ratio of 0.75 , a Reduction ratio of 0.2 and the initial feed of $300 \mathrm{~mm}$. It is consistent with the theoretical results from reference [7], namely, under the condition of a relatively narrow anvil width, the increasing of the relative feed reduces the end-face dent.

To analyze the data in above tables scientifically is an important step in the scheme design. Here the extremum 
difference analysis was used [16]. The extremum differences calculated from the end-face dent depths can be used to scientifically and accurately analyze the primary and secondary factors affecting the end-face dent. Tab. 3 gives the end face dent depths and their extremum differences.

\begin{tabular}{|c|c|c|c|c|}
\hline $\begin{array}{l}\text { Scheme } \\
\text { number }\end{array}$ & $\begin{array}{l}\text { Reduction } \\
\text { ratio A / \% }\end{array}$ & $\begin{array}{l}\text { Anvil width B } \\
\text { / mm }\end{array}$ & $\begin{array}{c}\text { Feed C/ } \\
\mathrm{mm}\end{array}$ & $\begin{array}{c}\text { End-face dent } \\
\text { depth / mm }\end{array}$ \\
\hline 1 & 10 & 500 & 300 & 34.41 \\
\hline 2 & 10 & 750 & 390 & 44.90 \\
\hline 3 & 10 & 1000 & 490 & 32.40 \\
\hline 4 & 15 & 500 & 390 & 68.15 \\
\hline 5 & 15 & 750 & 490 & 64.86 \\
\hline 6 & 15 & 1000 & 300 & 40.40 \\
\hline 7 & 20 & 500 & 490 & 52.63 \\
\hline 8 & 20 & 750 & 300 & 20.94 \\
\hline 9 & 20 & 1000 & 390 & 58.63 \\
\hline$K_{1}$ & 111.71 & 155.19 & 5.75 & \\
\hline$K_{2}$ & 181.41 & 173.41 & 171.68 & \\
\hline$K_{3}$ & 132.2 & 131.43 & 149.89 & \\
\hline$k_{1}$ & 37.24 & 51.73 & 31.92 & \\
\hline$k_{2}$ & 57.80 & 43.57 & 57.23 & \\
\hline$k_{3}$ & 44.07 & 43.81 & 49.97 & \\
\hline $\begin{array}{l}\text { Very } \\
\text { poor }\end{array}$ & 20.56 & 8.16 & 25.31 & \\
\hline
\end{tabular}

For factor $A$ with level 1, i.e. the reduction ratio was $10 \%$, the average value of end-face dent depth was taken from the schemes $1,2,3$. Here $K_{i}$ denotes the sum and the average is denoted as $k_{i}=K_{i} / 3$.

$K_{1}^{A}=34.41+44.9+32.4=111.71$

$k_{1}^{A}=\frac{K_{1}^{A}}{3}=37.24$

In the same way, for factor $A$ with level 2, the following can be achieved:

$K_{2}^{A}=68.15+64.86+40.4=173.41$

$k_{2}^{A}=\frac{K_{2}^{A}}{3}=57.80$

For factor $A$ with level 3,

$K_{3}^{A}=52,63+20,94+58,63=132.2$

$k_{3}^{A}=\frac{K_{3}^{A}}{3}=44,07$

$K_{3}^{A}=52.63+20.94+58.63=132.2$

$k_{3}^{A}=\frac{K_{3}^{A}}{3}=44.07$

$K_{1}^{A}$ reflected the influence of the factor $A$ with level 1 mainly. $K_{2}^{A}$ reflected the influence of the factor $A$ with level 2 mainly. $K_{3}^{A}$ reflected the influence of the factor $A$ with level 3 mainly.

The differences between $k_{1}^{A}, k_{2}^{A}$ and $k_{3}^{A}$ can be seen as the result of factor $A$ taking three different levels, which reflects the uniformity comparability of the orthogonal design.

The same method was used to analyze factors $B$ and $C$ and the following results can be obtained:

Results for factor $B$ :

$K_{1}^{B}=34.41+68.15+52.63=155.19$

$k_{1}^{B}=\frac{K_{1}^{B}}{3}=51.73$

$K_{2}^{B}=44.9+64.86+20.94=130.7$

$k_{2}^{B}=\frac{K_{2}^{B}}{3}=43.57$

$K_{3}^{B}=32.4+40.4+58.63=131.43$

$k_{3}^{B}=\frac{K_{3}^{B}}{3}=43.81$

Results for factor $C$ :

$K_{1}^{C}=34.41+40.4+20.94=95.75$

$k_{1}^{C}=\frac{K_{1}^{C}}{3}=31.92$

$K_{2}^{C}=44.9+68.15+58.63=171.68$

$k_{2}^{C}=\frac{K_{2}^{C}}{3}=57.23$

$K_{3}^{C}=32.4+64.86+52.63=149.89$

$k_{3}^{C}=\frac{K_{3}^{C}}{3}=49.97$

The difference between the maximum and minimum of $k_{1}, k_{2}, k_{3}$ is called the extremum difference:

For factor $A$, the extremum difference = $k_{2}^{A}-k_{1}^{A}=57.80-37.24=20.56$.

For factor $B$, the extremum difference $=$ $k_{1}^{B}-k_{2}^{B}=51.73-43.57=8.16$.

For factor $C$, the extremum difference = $k_{2}^{C}-k_{1}^{C}=57.23-31.92=25.31$.

According to the extremum difference analysis, the factor with a big extremum difference is the primary factor, which has a great influence on the simulation scheme results. The factors with smaller extremum differences are the secondary factors, which have less influence on the 
simulation scheme results. According to the extremum differences, the factors in the order of influence are $C-A-B$. Therefore, the primary factor influencing the endface dent during the stretching of shaft forgings is the feed. The Reduction ratio has less influence and the anvil width has the least. As a result, during the stretching of heavy forgings, the feed should be considered first, then the Reduction ratio, and finally, the anvil width ratio.

\section{INDUSTRIAL PRODUCTION COMPARISON}

China first heavy industries (CFHI) also adopted flat upper and $\mathrm{V}$-shaped lower anvils to produce heavy forgings [7]. Because the anvils of $1200 \mathrm{~mm}$ in width were used and relative feeds were small, the end-face dent was severe. The improved process plan was as follows: making the handle for the clamp to hold $\rightarrow$ cutting the hot top $\rightarrow$ upsetting with dedicated upsetting cover plates $\rightarrow \mathrm{KD}$ stretching $\rightarrow$ upsetting with dedicated upsetting cover plates $\rightarrow$ stretching with $850 \mathrm{~mm}$ wide flat upper and Vshaped lower anvils $\rightarrow$ remove unwanted material to complete forging. The flat upper and $\mathrm{V}$-shaped lower anvils with a relatively narrow width of $850 \mathrm{~mm}$ were used and the relative feed was increased, there was no obvious end-face dent seen. The forging after unwanted material was removed is shown in Fig. 9.



Figure 9 End-face produced with improved process

The A3B2C1 scheme is similar to the actual production scheme adopted by CFHI in which the anvil width was $850 \mathrm{~mm}$ and the initial feed was $300 \mathrm{~mm}$. The actual production indicates that with such a scheme the end-face dent was significantly reduced. The agreement between the theoretical analysis and the actual industrial production proved that the proposed optimized process scheme is practical.

\section{CONCLUSIONS}

(1) The finite element software DEFORM-3D was used to carry out the numerical simulation of the stretching process with flat upper and V-shaped anvils, which avoids physical experiments. The agreement between the theoretical analysis and the actual industrial production verified the rationality and correctness of the finite element software simulation.

(2) The anvil width, reduction ratio and feed were selected as the influencing factors to design the orthogonal table. Accordingly, simulations were carried out and their end-face dent depths were achieved. The optimized process scheme was obtained through orthogonal schemes and numerical simulations, in which the $\mathrm{A} 3 \mathrm{~B} 2 \mathrm{C} 1$ parameter combination adopted an anvil width of $750 \mathrm{~mm}$, an initial feed of $300 \mathrm{~mm}$, and a reduction ratio of 0.2 , which is similar to the actual production scheme adopted by CFHI in which the anvil width was $850 \mathrm{~mm}$ and the initial feed was $300 \mathrm{~mm}$. It reduced the end-face dent.

(3) The extremum difference analysis indicates that among the three major factors affecting the end-face dent, the most influential one is the feed, then the reduction ratio, and the least influential is the anvil width ratio.

\section{Acknowledgement}

Thanks to the support of Guangdong Special Fund for Basic and Applied Research (NO. 1614050000138) and Students Innovation Training Program of Zhongshan Institute, University of Electronic Science and Technology of China (NO. 2019CXXL057) and Quality Resources Sharing Course "Engineering Materials and Forming Technique" (Department of Education of Guangdong Province, Higher Education (2016) NO. 233) and Guangdong Province 2016 Higher Education Teaching Reform Project (NO. 28286) and Guangdong New Engineering Research and Practice Projects NO. 41 (Department of Education of Guangdong Province, Higher Education (2017) NO. 170) and $13^{\text {th }}$ Five-Year Plan of Educational Science of Guangdong Provincial Department of Education (NO. 2018GXJK244).

\section{REFERENCES}

[1] Kawai, M. (1997). On the Mannesmann effect appearing in the course of solid forging of steel ingot. Proceedings of $8^{\text {th }}$ International Forgemasters Meeting, Kyoto.

[2] Ying, C., Zhi-ping, Z., \& Yi, B. (2000). Modeling research on the anvil angle of mandrel drawing for RPV forging at room temperature. Journal of Plastic Engineering, 7(3), 5256.

[3] Cook, P. M. (1959). Dependence of Mechanical Properties of Forgings on local strain. Journal of the Iron and Steel Institute, 4, 250-252.

[4] Behrens, B. A., Volk, W., Maier, D. et al. (2020). A Combined Numerical and Experimental Investigation on Deterministic Deviations in Hot Forging Processes. Procedia Manufacturing, 47, 295-300. https://doi.org/10.1016/j.promfg.2020.04.231

[5] Chen-chao, Z. (2012). Head face throat defect of round billet large forgings during stretching process. Dissertation, Yanshan University.

[6] Meng-han, W., Rui, W., Long, H., Qing, L., \& Peng, Z. (2014). Formation Mechanism and Control technology of head face throat defect during large forgings swaging. Hot Working Technology, 19, 103-106.

[7] Li-zhong, W. \& Da, Z. (2016). Optimization of forging process for Spindle Forgings. Metal working, 13, 65-66.

[8] Ming-qi, D. (2019). Study on Deformation Behavior and duality control of Mandrel Forging Process. Shandong University.

[9] Yin, W. \& Yu-cun, Z. (2018). The Length Dimension Measurement for Large Hot Forgings Based on the Recognition of Green Laser. ACTA Metrologica Sinica, 39(3), 316-320.

[10] Yang. L. (2018). Key Technology Study on Image Processing Methods in Stereo Vision Measurement of Large Hot Forging. Dalian University of Technology.

[11] Jin-gang, Z. \& Fa-ming, Z. (2019). Technology of Thermal on Line Automated 3D Measurement and Precision Detection of Vehicle Axles. New Technology \& New 
Process, 2019(08), 77-80

[12] Jin, H., Qing-xuan, W., \& Hao, L. (2019). Research on Online Measurement of Noncontact Forging Based on Laser. Heavy Casting and Forging, (03), 50-51, 54.

[13] Zhang, Y., Wang, Y., Liu, Y. et al. (2019). A concentricity measurement method for large forgings based on laser ranging principle. Measurement, 147, Article 106838. https://doi.org/10.1016/j.measurement.2019.07.066

[14] Xian-bin, F., Shu, M, Yu-cun, Z., et al. (2020). A new method of processing laser scanning data of radial section dimensions for ring forgings. Measurement, 153, Article 107430. https://doi.org/10.1016/j.measurement.2019.107430

[15] Qin-xiang, X., Yu-lin, H., Hui-xing, S., Wei-liang, L., Yong, P. (2010). Study on internal quality and size precision of long-axis heavy forging after chamfering and rounding. Forging \& Stamping Technology, 2010(02)

[16] Wei, H., Wei-dong, X., \& Bin, T. (2012). Optimization test design method and data analysis. Bei Jing: Chemical Industry Press.

\section{Contact information:}

Liyong NI

University of Electronic Science and Technology of China,

Zhongshan Institute, Zhongshan, 528402, China

\section{Longjiang NIU}

(Corresponding author)

School of Mechanical Engineering,

Shanghai Dianji University, Shanghai, 201306 China

Email: nly_uest@163.com

\section{Daoxiang QIAN}

V-Strong Electronics CO., LTD

Guangdong Shenzhen 518048, China

\section{Suoqing YU}

Xingtai Polytechnic College,

Xingtai, 054035, China

\section{Chenyu YE}

University of Electronic Science and Technology of China Zhongshan Institute, Zhongshan, 528402, China

\section{Yibin CAI}

Liaoning Zhongwang Group CO., LTD,

Shenzhen 518110, China 